\title{
Difluoroboron Curcumin Complex: A Study on Determination of Acidity Constants and Quantitative Analysis of Arsenic(III)
}

\author{
Nguyen Quoc Thang ${ }^{1}$, Tran Nguyen Minh An ${ }^{1^{*}}$, Le Thi Thanh Tran ${ }^{2}$, Do Tam Nhan ${ }^{3}$, \\ Mai Ngoc Tan ${ }^{4}$, and Le Van Tan ${ }^{1 *}$ \\ ${ }^{1}$ Faculty of Chemical Engineering, Industrial University of Ho Chi Minh City, Ho Chi Minh City, Vietnam \\ ${ }^{2}$ Chemical and Environmental Science Department, Dalat University, Lam Dong Province, Vietnam \\ ${ }^{3}$ Nuclear Research Institute, Lam Dong Province, Vietnam \\ ${ }^{4}$ Faculty of Retraining and Continuing Education, Dak Nong Community College, Dak Nong Province, Vietnam
}

\section{* Corresponding author: \\ email: trannguyenminhan@iuh.edu.vn*; levantan@iuh.edu.vn*}

Received: June 24, 2021

Accepted: August 16, 2021

DOI: $10.22146 /$ ijc. 66990

\begin{abstract}
In this study, the complex of difluoroboron curcumin (BF ${ }_{2}$-Cur) has been synthesized and characterized via the combination of Boron trifluoride-diethyl etherate $\left(\left(\mathrm{C}_{2} \mathrm{H}_{5}\right)_{2} \mathrm{OBF}_{3}\right)$ and curcumin. However, the new dissociation constants, $p K_{a 1}$ and $p K_{a 2}$ of the $\mathrm{BF}_{2}$-Cur complex, have been indicted by the values of $8.44 \pm 0.16$ and $9.76 \pm 0.13$, respectively. On the other hand, the reagent was also used to determine As(III) in aqueous solutions by $U V$-Vis spectrophotometry. As a result, the method was validated for accuracy, precision, linearity, and sensitivity, and the linear range was from 1.0 to 25.0 $\mu \mathrm{mol} / \mathrm{L}$, with the linear regression, $A=0.0027 \mathrm{C}+0.0106$, correlation coefficient $R^{2}=$ 0.9969. Besides, the limit of detection (LoD) and limit of quantification (LoQ) were determined as 0.83 and $2.10 \mu \mathrm{mol} / \mathrm{L}$, respectively. Thus, the developed method is successfully used for quantitative analysis of total arsenic in wastewater by reducing As(V) to As(III), then determining As(III) with high accuracy results.
\end{abstract}

Keywords: $\mathrm{BF}_{2}$-Cur; total arsenic; UV-Vis spectrophotometry; the conformation of complex; UFF

\section{- INTRODUCTION}

Water is an essential component for maintaining life on earth. However, water quality declines seriously, and water contamination has become the most concerning global environmental issue. Polluted water includes many toxic components, such as organic and inorganic wastages [1-2], surfactants [3], synthetic dyes [4], and heavy metals [5]. Among various heavy metals found in this water, arsenic is determined as toxic metal, which has the most hazardous effects on living organisms. Once exposed to arsenic, various adverse health effects can be caused, including dermal changes and respiratory, cardiovascular, gastrointestinal, genotoxic, mutagenic, and carcinogenic effects.

The mobility and toxicity of arsenic have been determined by its oxidation state [6]. The inorganic arsenic exists in four stable oxidation states of $-3,0,+3$, and +5 [7]. Besides, the most prevalent forms found in aqueous solutions are the pentavalent arsenate ion, As(V), and the trivalent arsenite ion, As(III) [8]. The total arsenic analysis [As(III) + As(V)] is very crucial, and a reduction of $\mathrm{As}(\mathrm{V})$ to $\mathrm{As}(\mathrm{III})$ is required for correct analysis [9]. The analysis of arsenic is assessed to be essential because of its severe threats and risk to human health as arsenic-contaminated drinking water can be supplied through underground sources, especially in rural areas where another alternative water supply is not widely available. Various methods have been applied for determining the content of arsenic in water, such as ICP-OES [10], Electrothermal Atomic Absorption Spectrometry [11], VGA-AAS [10], AFS [12], ICP-AES [13], NAA [14], CA [15], and ASV [16]. 
On the other hand, curcumin is a natural polyphenol compound from the root of Curcuma longa $L$. (Zingiberaceae). It has many essential bioactivities reported in previous articles, including anti-inflammatory, anticancer, antioxidant, antivirus, and cytoprotective activities. Otherwise, it has been used to constitute complexes with metal ions, which have different properties than one free form of curcumin [17-18].

The synthetic strategies, structure identification, and medicinal applications of the metal complexes of curcumin have been studied [19-20]. Among these complexes, the difluoroboron curcumin $\left(\mathrm{BF}_{2}\right.$-Cur $)$ complex has been widely used to analyze toxic environments. This complex is combined with digital image analysis for semi-quantitative analysis of arsenic [21]. Then, As(III) can be determined in water samples using UV-Visible spectrophotometry and naked-eye detection [22]. In fact, the $\mathrm{BF}_{2}$-Cur has offered a remarkably promising ability of cyanide detection with 66-fold enhancement in aqueous media $\left(\mathrm{CH}_{3} \mathrm{CN} / \mathrm{H}_{2} \mathrm{O}\right.$ 4:1 $\mathrm{v} / \mathrm{v}$ ) [23], and it has been used as fluorophores to construct fluorescent probes, which were screened for their response to cyanide, hydrogen sulfide, hypochlorite, and bisulfite ion in aqueous solutions [24].

The difluoroboron-derivatized curcumins have been used as Near-Infrared Probes for in vivo detection of $\beta$-amyloid deposits [25]. Some of them have focused on the digital image colorimetry (DIC) of the difluoroboroncurcumin doped as starch film $\left(\mathrm{BF}_{2}\right.$-Cur-film) for the detection of $A s($ III) in aqueous and resin beads. Its difluoroboron complex has been used as fluorophores to construct fluorescent probes with $\beta$-diketone or phenolic hydroxyl groups as recognition sites [26-28]. Because the variety of applications of the difluoroboron complex interested us, our research groups have been working on organic indicators. In this research, we not only conducted the novel dissociation constants, $\mathrm{pK}_{\mathrm{a} 1}, \mathrm{pK}_{\mathrm{a} 2}$ of the $\mathrm{BF}_{2}$ Cur, but also explored its feasibility in analyzing the total amount of As in water via the oxidizing As(V) to As(III).

\section{- EXPERIMENTAL SECTION}

\section{Materials}

The $\mathrm{BF}_{2}$ and curcumin were purchased from Sigma
Aldrich, Singapore, while other chemicals and solvents were purchased from Merck, Darmstadt, Germany. In this study, the chemicals were used in analytical grade; thus, they could be used without further purification.

\section{Instrumentation}

UV-Vis absorption spectra were recorded on UVVis Evolution 60, THERMO (USA), and the $\mathrm{pH}$ of solutions was detected using pH S220 Seven Compact, Ion-Mettler Toledo (USA). FT-IR spectrum was performed on Jasco 4700 (Japan). Besides, the NMR spectra were recorded on one Bruker Avance-500 MHz, external TMS, and the HR-MS was performed on a 6200 series TOF/6500 series Q-TOF B.06.01 (B6172 SP1). In addition, Titration Equipment was tested on Metrohm, Model 888-Switzerland, and analysis balance (Minimum Display 0.1 mg-USA). Finally, the most stable conformation complex, $\mathrm{BF}_{2}$-Cur, was calculated using the Avogadro package via UFF (Universal Force Field) method.

\section{Procedure}

\section{Synthetic of $\mathrm{BF}_{2}$-Cur complex}

The $\mathrm{BF}_{2}$-Cur was synthesized by following [22-23] and tested by TLC when the reaction was completed. The structures of the $\mathrm{BF}_{2}$-Cur complex and the base forms of Cur- $\mathrm{BF}_{2}$ with $\mathrm{AsO}_{3}{ }^{3-}$ ion were analyzed by ${ }^{1} \mathrm{H}-$ $\mathrm{NMR}$ and HR-MS spectra. The base forms of complex Cur- $\mathrm{BF}_{2}$ or Cur- $\mathrm{BF}_{2}$ with $\mathrm{Cur}-\mathrm{BF}_{2}$ with $\mathrm{AsO}_{3}{ }^{3-}$ ion were investigated by adding one mmol of Cur- $\mathrm{BF}_{2}$ and two mmol of $\mathrm{AsO}_{3}{ }^{3-}$ ion to $0.5 \mathrm{~mL}$ of the $\left(\mathrm{CD}_{3}\right)_{2} \mathrm{C}=\mathrm{O}, \mathrm{d}_{6}$ commercial deter solvent.

\section{Determination of acidity constants for BF2-Cur complexes}

First, $6.087 \times 10^{-3} \mathrm{M}$ of $\mathrm{BF}_{2}$-Cur solution in ethanol and $10^{-3} \mathrm{M}$ of $\mathrm{NaOH}$ solution were prepared. Then, the $\mathrm{V}_{\mathrm{o}}$ volume of $2.5 \mathrm{~mL}$ of $6.087 .10^{-3} \mathrm{M} \mathrm{BF}_{2}$-Cur solution was titrated with $10^{-3} \mathrm{M}$ of $\mathrm{NaOH}$ solution using a 798 MPT Titrino using a syringe pump. The titration $(\mathrm{NaOH})$ was added to titrate $\left(\mathrm{BF}_{2}-\mathrm{Cur}\right)$ in increments of $0.01 \mathrm{~mL}$, with a pause of $7 \mathrm{sec}$. The $\mathrm{pK}_{\mathrm{a}}$ values were calculated from the experimental based on data points $\left[\left(\mathrm{V}_{\mathrm{i}}, \mathrm{pH}_{\mathrm{i}}\right)\right.$ according to the Kostrowicki and Liwo algorithm [29-30]. The equation was as follows. 


$$
\mathrm{pK}_{\mathrm{a}}=\mathrm{pH}-\log \frac{\left[\mathrm{Na}^{+}\right]+\left[\mathrm{H}^{+}\right]-\left[\mathrm{OH}^{-}\right]}{\mathrm{C}_{\text {Curcu min }-\mathrm{BF}_{2}}-\left[\mathrm{Na}^{+}\right]-\left[\mathrm{H}^{+}\right]+\left[\mathrm{OH}^{-}\right]}
$$

whereas $\left[\mathrm{Na}^{+}\right]=$the amount of the $\mathrm{NaOH}$ solution added, $\left[\mathrm{H}^{+}\right]=10^{-\mathrm{pH}}$, and $\left[\mathrm{OH}^{-}\right]=10^{14-\mathrm{pH}}$. All measurements were conducted at $\mathrm{T}=25 \pm 1{ }^{\circ} \mathrm{C}$.

\section{Determination of the total content of arsenic in the water samples [28]}

To analyze the total content in the sample, As(V) needed to be reduced to As(III), then the same analytical procedure was proceeded for As(III). The whole method to analyze the total As can be presented as follows.

(i) A sample of $50 \mathrm{~mL}$ wastewater was accurately pipetted into a flask of Soxhlet. Then, $5 \mathrm{~mL}$ purity $\mathrm{H}_{2} \mathrm{SO}_{4}$ and $5 \mathrm{~mL}$ of $\mathrm{H}_{2} \mathrm{O}_{2}$ were added to the wastewater. It was heated until a large quantity of white smoke $\left(\mathrm{H}_{2} \mathrm{SO}_{4}\right)$ was released. The solutions were cooled to room temperature, and $\mathrm{NaOH}$ was used to adjust $\mathrm{pH}$ 7.5.

(ii) To reduce $\mathrm{As}(\mathrm{V})$ to $\mathrm{As}(\mathrm{III})$ : About $50 \mathrm{~mL}$ of the sample was poured into a round-bottomed flask, and then it was added with $20 \mathrm{~mL}$ of hydrochloric acid and $4 \mathrm{~mL}$ of the potassium iodide (KI) in an ascorbic acid solution to the sample flask. The mixture was heated gently at $50{ }^{\circ} \mathrm{C}$ for $15 \mathrm{~min}$. The solution was let cool down, transferred entirely to a $100 \mathrm{~mL}$ volumetric flask, and makeup to $100 \mathrm{~mL}$ with water. The final solution was used directly for the determination of total As.

(iii) $5 \mathrm{~mL}$ of the final solution was pipetted into a $25 \mathrm{~mL}$ flask, and then it was added with $10 \mathrm{~mL}$ of ethanol, 5 $\mathrm{mL}$ of $\mathrm{BF}_{2}$-Cur, and diluted to $25 \mathrm{~mL}$ using ethanol. Blank and calibration solutions were prepared in a similar way to achieve the same final concentrations. After $30 \mathrm{~min}$, these solutions were used directly for the determination of total As.

(iv) The determination of As(III) in the water samples. 20 $\mathrm{mL}$ of filtered water was placed into a volumetric flask of $25 \mathrm{~mL}$, and then the indicator paper was used to adjust $\mathrm{pH}=8$, and the solution was filled up to $25 \mathrm{~mL}$ with distilled water to create the sample at $\mathrm{pH}=8$. Then, $5 \mathrm{~mL}$ of reagent $\mathrm{BF}_{2}-\mathrm{Cur} 10 \mathrm{ppm}$ was aspirated into $5 \mathrm{~mL}$ of the sample at $\mathrm{pH}=8$ in another $25 \mathrm{~mL}$ volumetric flask. Then ethanol was filled up to $25 \mathrm{~mL}$ and measured by UV-Vis spectrometry at $632 \mathrm{~nm}$.

(v) On the other hand, a wastewater sample containing As(III) and As total were analyzed concurrently with the HPLC-ICP-MS method to compare the results.

\section{- RESULTS AND DISCUSSION}

\section{The Acidity Constants for $\mathrm{BF}_{2}$-Cur Complexes}

The $\mathrm{pK}_{\mathrm{a}}$ values were calculated from the reaction of $\mathrm{NaOH}$, which titrated the complex. The $\mathrm{pK}_{\mathrm{a}}$ was calculated from the experimental data of points according to the Kostrowicki and Liwo algorithm, corresponding to $\Delta \mathrm{pH} / \Delta \mathrm{V}-\mathrm{V}$ curve. The $\Delta \mathrm{pH} / \Delta \mathrm{V}-\mathrm{V}$ curve has indicated that it has had two $\mathrm{pH}$ transitions at volume $\mathrm{NaOH} 3.20 \mathrm{~mL}$ and $6.15 \mathrm{~mL}$ and proved that the $\mathrm{BF}_{2}$-Cur complex had a diprotic acid form. Based on the titration curve of the $\mathrm{BF}_{2}$-Cur complex (presented in the form of weak acids), the values of $\mathrm{pK}_{\mathrm{a}}$ were calculated.

The $\mathrm{pK}_{\mathrm{a} 1}$ and $\mathrm{pK}_{\mathrm{a} 2}$ of the standardized $\mathrm{BF}_{2^{-}}$ curcumin complex in the ethanol and water mixed solvent system were $8.44 \pm 0.16$ and $9.76 \pm 0.13$, respectively. The complex acid was found to be dissociated to $K_{a 1}$ and $K_{a 2}$ in solutions. As shown in Fig. 4 , the value of $\mathrm{pK}_{\mathrm{a} 1}$ was determined based on our calculation via titration and explained the resonance effects, the positive resonance, and $+\mathrm{R}$ of hydroxyphenyl of an aromatic ring. The resonance ring system made one hydrogen atom (left side) of the phenolic hydroxy group of A ring more flexible, as indicated in Fig. 4. Due to this reason, the deprotonation of the A ring occurred more quickly than the $B$ ring. This positive resonance, $+\mathrm{R}$, only appeared for the phenolic of A and without $\mathrm{B}$ ring.

These results are pretty consistent with the previous results of Margarita Bernabé-Pineda on curcumin [26]. This article reported the acetylacetone group and two groups of hydroxyl phenolic of curcumin structure, which corresponded to the values of $\mathrm{pK}_{\mathrm{al}}=$ $8.38 \pm 0.04 \mathrm{pK}_{\mathrm{a} 2}=9.88 \pm 0.02$, and $\mathrm{pK}_{\mathrm{a} 3}=10.51 \pm 0.01$, respectively, and they were performed in the Fortran program. The value of $\mathrm{pK}_{\mathrm{a} 1}$ in the article [26] was relative to an enol equivalent in base media, and our research did not explain based on this site. For the $\mathrm{BF}_{2}$-Cur complex, 
we determined the $\mathrm{pK}_{\mathrm{al}}$ and $\mathrm{pKa}_{2}$ to be $8.44 \pm 0.16$ and $9.76 \pm 0.13$, respectively. The $\mathrm{pK}_{\mathrm{a} 1}$ and $\mathrm{pK}_{\mathrm{a} 2}$ values of the $\mathrm{BF}_{2}$-Cur complex were compared to $\mathrm{pK}_{\mathrm{a} 2}$ and $\mathrm{pK}_{\mathrm{a} 3}$ of Cur in the article.

The results indicated that the Cur- $-\mathrm{BF}_{2}$ complex had more acidic than curcumin. It was explained that the solvate was formed from the hydrogen atoms of the solvent molecules such as ethanol and water and one negative $\mathrm{B}$ atom of $\mathrm{Cur}-\mathrm{BF}_{2}$, as seen in Fig. 4 [23]. That the protonations of positive hydrogens of the solvent molecules and $\mathrm{EtOH}$ formed around a negative boron atom led to the decrease of the negative electron density on it, supported the $+\mathrm{R}$ effect of phenolic hydroxy groups (EDG) at $\mathrm{A}$ ring in Fig. 4, and increased the acidic property of Cur- $\mathrm{BF}_{2}$ complex.

BF $_{2}$-Cur: ( ${ }^{1} \mathrm{H}-\mathrm{NMR}$-acetone, $\mathrm{d}_{6}, 25{ }^{\circ} \mathrm{C}$, TMS), $\delta$ (ppm): 8.67 (s, 2H, Ar-O프) 7.87 (d, $J=15.5 \mathrm{~Hz}, 2 \mathrm{H}$, alkene proton, $\mathrm{H}-9, \mathrm{H}-10), 7.46$ (d, J = $1.9 \mathrm{~Hz}, 2 \mathrm{H}, \mathrm{Ar}-\mathrm{H}, \mathrm{H}-6, \mathrm{H}-$ 6'), 7.34 (dd, $J=8.3, J=1.9 \mathrm{~Hz}, 2 \mathrm{H}, \mathrm{H}-2, \mathrm{H}-2$ '), 6.93 (d, $J$ $=15.6 \mathrm{~Hz}, 2 \mathrm{H}$, alkene proton, $\mathrm{H}-7, \mathrm{H}-8), 6.92(\mathrm{~d}, J=8.2$ $\mathrm{Hz}, 2 \mathrm{H}, \mathrm{H}-3, \mathrm{H}-3$ ') 6.36 (s, 1H, H-11), 3.93 (s, 6H, $\left.2 \mathrm{OCH}_{3}\right)$. The 19 resonance proton signals were conformed via ${ }^{1} \mathrm{H}-\mathrm{NMR}$ spectrum.
$\mathrm{BF}_{2}$-Cur-AsO ${ }_{3}$ : ( ${ }^{1} \mathrm{H}-\mathrm{NMR}$-acetone, $\mathrm{d}_{6}, 25{ }^{\circ} \mathrm{C}$, TMS), $\delta$ (ppm): 7.94 (d, $J=15.6 \mathrm{~Hz}, 2 \mathrm{H}$, alkene proton, $\mathrm{H}-9, \mathrm{H}-$ 10), 7.46 (d, $J=1.8 \mathrm{~Hz}, 2 \mathrm{H}, \mathrm{Ar}-\mathrm{H}, \mathrm{H}-6, \mathrm{H}-6$ '), 7.34 (dd, $J$ $\left.=8.2, J=1.8 \mathrm{~Hz}, 2 \mathrm{H}, \mathrm{H}-2, \mathrm{H}-2^{\prime}\right), 6.93(\mathrm{~d}, J=8.2 \mathrm{~Hz}, 2 \mathrm{H}$, H-3, H-3'), 6.92 (d, $J=15.6 \mathrm{~Hz}, 2 \mathrm{H}$, alkene proton, $\mathrm{H}-7$, $\mathrm{H}-8), 6.36$ (s, $1 \mathrm{H}, \mathrm{H}-11), 3.93$ (s, $\left.6 \mathrm{H}, 2 \mathrm{OCH}_{3}\right)$. The 17 resonance proton signals were assigned via ${ }^{1} \mathrm{H}-\mathrm{NMR}$ spectrum.

The NMR spectrum of complex $\mathrm{BF}_{2}$-Cur indicated the resonances of 19 protons. As compared to the NMR spectra results in Fig. 1 and Fig. 2, the $\mathrm{BF}_{2}-\mathrm{Cur}-\mathrm{AsO}_{3}$ complex had 2 protons of hydroxy phenolic reduced when two equivalent mols of base $\mathrm{AsO}_{3}{ }^{3-}$ was added to the number of mol of Cur- $\mathrm{BF}_{2}$. It was proved by two disappeared protons at $8.67 \mathrm{ppm}$ in two NMR spectra, as shown in Fig. 2. The values of coupling constants of alkene protons ( $J$, coupling constant of vinyl protons from $12-18 \mathrm{~Hz}$, trans-isomer and $6-12 \mathrm{~Hz}$, cis isomer) were calculated in the range of $15.5-15.6 \mathrm{~Hz}$, which demonstrated the configuration of the complexes of Cur- $\mathrm{BF}_{2}, \mathrm{Cur}-\mathrm{BF}_{2}-\mathrm{AsO}_{3}$ with the conformation of trans and trans in 2 alkenyl groups [23,31].

The novel mechanism forming of $\mathrm{pK}_{\mathrm{a} 1}$ and $\mathrm{pK}_{\mathrm{a} 2}$ of

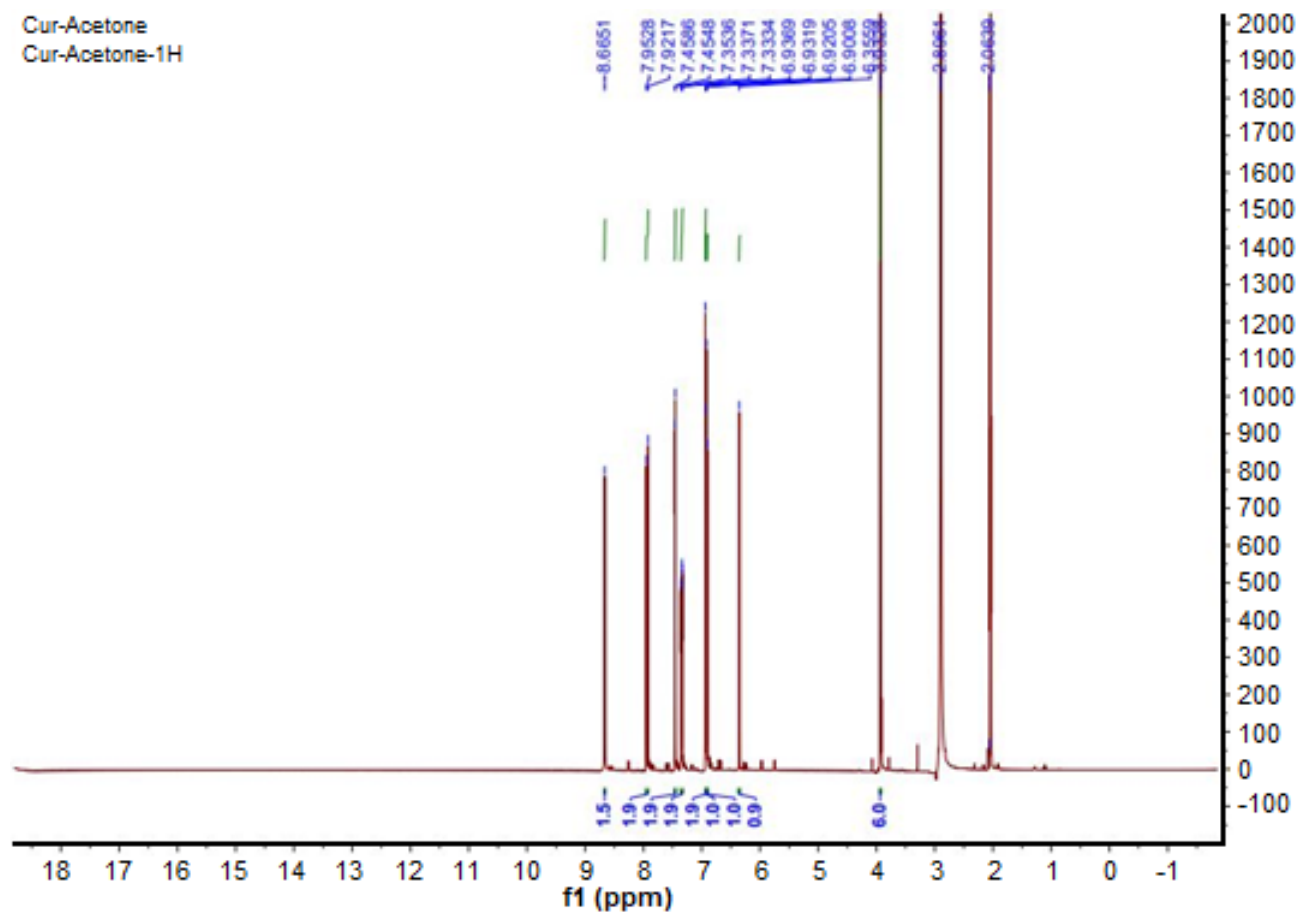

Fig 1. The ${ }^{1} \mathrm{H}-\mathrm{NMR}, 500 \mathrm{MHz}$ in acetone- $\mathrm{d}_{6}$ of complexes the $\mathrm{BF}_{2}$-Cur 


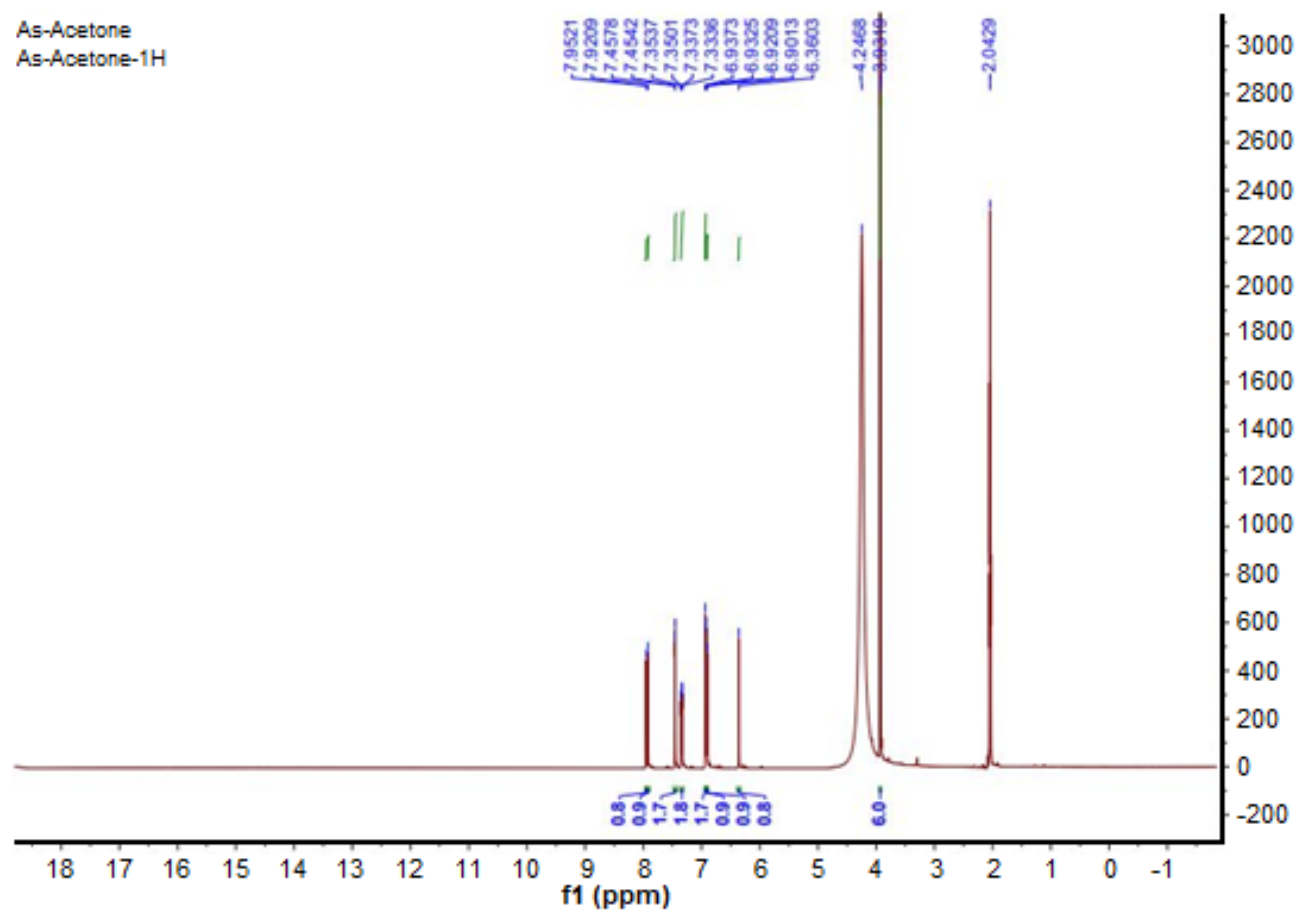

Fig 2. The ${ }^{1} \mathrm{H}-\mathrm{NMR}, 500 \mathrm{MHz}$ in acetone- $\mathrm{d}_{6}$ of complexes the $\mathrm{BF}_{2}-\mathrm{Cur}-\mathrm{AsO}_{3}$

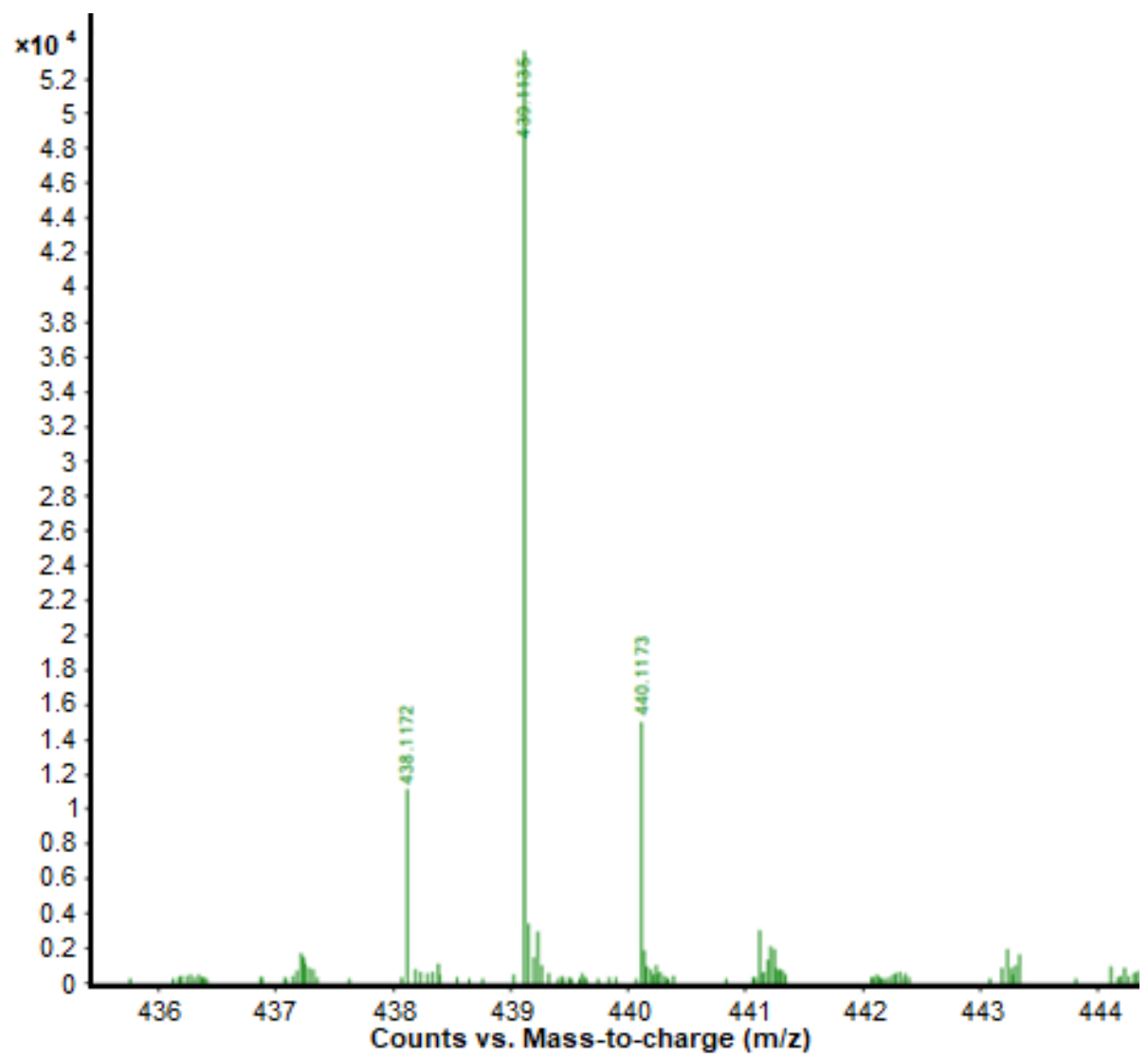

Fig 3. The HR-MS of $\mathrm{BF}_{2}-\mathrm{Cur}-\mathrm{AsO}_{3}$ 
$\mathrm{BF}_{2}$-Cur proposed by our research was based on the $+\mathrm{R}$ effect of one phenolic hydroxy bonding to A ring in Fig. 4. In Fig. 3, the HR-MS spectra (ESI) of $\mathrm{BF}_{2}-\mathrm{Cur}-\mathrm{AsO}_{3}$ showed the experiment value of the positive molecule ion, $\mathrm{m} / \mathrm{z}$, which was 439.1135 . This value corresponds to molecular ion, $[\mathrm{M}+2 \mathrm{H}+\mathrm{Na}]^{+}$. The calculation value was 439.1157 and confirmed that the molecular ion was $\mathrm{C}_{21} \mathrm{H}_{17} \mathrm{BF}_{2} \mathrm{O}_{6}{ }^{3-}$ when two mols of $\mathrm{AsO}_{3}{ }^{3-}$ added to the $1 \mathrm{~mol} \mathrm{BF}_{2}$-Cur complex solution.

As seen in Fig. 4, the phenolic hydroxy groups on the structure of the $\mathrm{BF}_{2}$-Cur complex and resonance effects on this structure determined what hydroxyl groups were corresponding to $\mathrm{K}_{\mathrm{a} 1}$ and $\mathrm{K}_{\mathrm{a} 2}$. The acid-base reactions between the complex $\mathrm{BF}_{2}$-Cur with $\mathrm{AsO}_{3}{ }^{3-}$ ion were proved by ${ }^{1} \mathrm{H}-\mathrm{NMR}$ and HR-MS spectra and conformed the most stable conformation of $\mathrm{BF}_{2}-\mathrm{Cur}_{\mathrm{BF}_{2}-}$ Cur- $\mathrm{AsO}_{3}$ was confirmed via ${ }^{1} \mathrm{H}-\mathrm{NMR}$ as seen in Fig. 1-3.

The configuration of the $\mathrm{BF}_{2}$-Cur complex was calculated based on the UFF method via the Avogadro package in Fig. 5, and the optimal energy value of the most stable conformation of $\mathrm{BF}_{2}$-Cur was $31.23 \mathrm{~kJ} \mathrm{~mol}^{-1}$ [32]. Fig. 5 shows the significant properties of the complex in calculation via Avogadro package exposed such angles as $\mathrm{F}_{2} \mathrm{BO}_{6}, \mathrm{O}_{6} \mathrm{BF}_{1}$, and $\mathrm{F}_{1} \mathrm{BO}_{5}$ of $109.56^{\circ}, 109.52^{\circ}, 109.25^{\circ}$, and $108.27^{\circ}$, respectively, formed a tetrahedral structure, $\mathrm{F}_{1} \mathrm{~F}_{2} \mathrm{BO}_{5} \mathrm{O}_{6}$ ( $\mathrm{B}$ atom in central tetrahedron). It was an irregular tetrahedral structure due to its different angles. Other angles were $\mathrm{F}_{1} \mathrm{BF}_{2}$ and $\mathrm{O}_{5} \mathrm{BO}_{6}$ in the values of $108.24^{\circ}$ and $111.34^{\circ}$, respectively.

The angle $\mathrm{O}_{5} \mathrm{BO}_{6}$ was $111.84^{\circ}$, which was the biggest value because the oxygen atoms have lone pairs, which increased its angle. The angles of $\mathrm{C}_{12} \mathrm{O}_{6} \mathrm{~B}$ and $\mathrm{C}_{10} \mathrm{O}_{6} \mathrm{~B}$ were $123.11^{\circ}$ and $124.57^{\circ}$, respectively, which indicated the $\mathrm{O}_{5} \mathrm{C}_{10} \mathrm{C}_{11} \mathrm{C}_{12} \mathrm{O}$ - $\mathrm{B}$ ring of complex $\mathrm{BF}_{2}$-Cur has nearly a plane structure. This structure of the planned ring affects the acidic ability of complex $\mathrm{BF}_{2}$-Cur via the $+\mathrm{R}$ effect of one phenolic hydroxy, which bounds to A ring. The bond length of $\mathrm{O}_{1}-\mathrm{H}_{1}$, one phenolic hydroxy bond, was longer than that of $\mathrm{O}_{3}-\mathrm{H}_{2}$, so that the hydro atom, $\mathrm{H}_{1}$, was more flexible than $\mathrm{H}_{2}$. The deprotonation on $\mathrm{O}_{1}$ $\mathrm{H}_{1}$ was easier than that of $\mathrm{O}_{3}-\mathrm{H}_{2}$. The bond lengths of $\mathrm{B}-$ $\mathrm{O}$ and $\mathrm{B}-\mathrm{F}$ were equal. The bond lengths of $\mathrm{C}-\mathrm{O}$, single bond, and $\mathrm{C}=\mathrm{O}$, a double bond was different because the orders' values were also different. The photophysical and photochemical phenomena of $\mathrm{BF}_{2}$ - $\mathrm{Cur}$ in the presence of $\mathrm{AsO}_{3}{ }^{3-}$ were assumed to undergo the deprotonation of phenolic hydroxyl groups by nitrile ion, $\mathrm{AsO}_{3}{ }^{3-}$.

The ${ }^{1} \mathrm{H}-\mathrm{NMR}$ spectra showed strong evidence to support this assumption, as shown in Fig. 1-2. According to the ${ }^{1} \mathrm{H}-\mathrm{NMR}$ spectra of $\mathrm{BF}_{2}-\mathrm{Cur}$ and $\mathrm{AsO}_{3}{ }^{3-}$, the phenolic hydroxyl protons at $8.66 \mathrm{ppm}$, completely

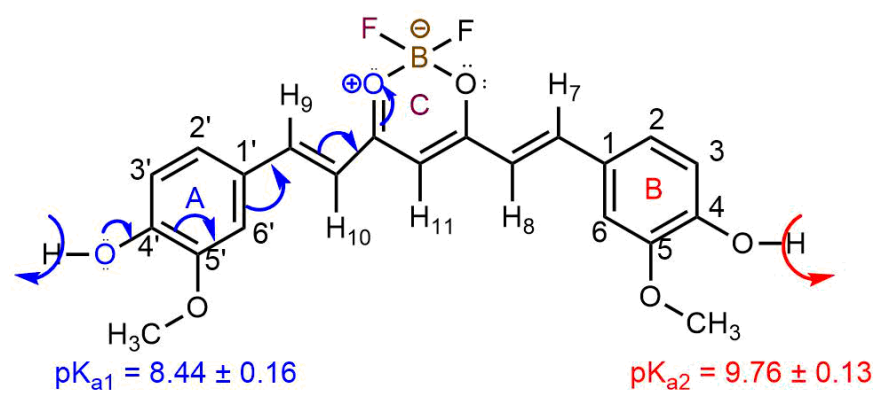

Fig 4. The resonance structure proposed of $\mathrm{BF}_{2}$-Cur$\mathrm{AsO}_{3}$ complex

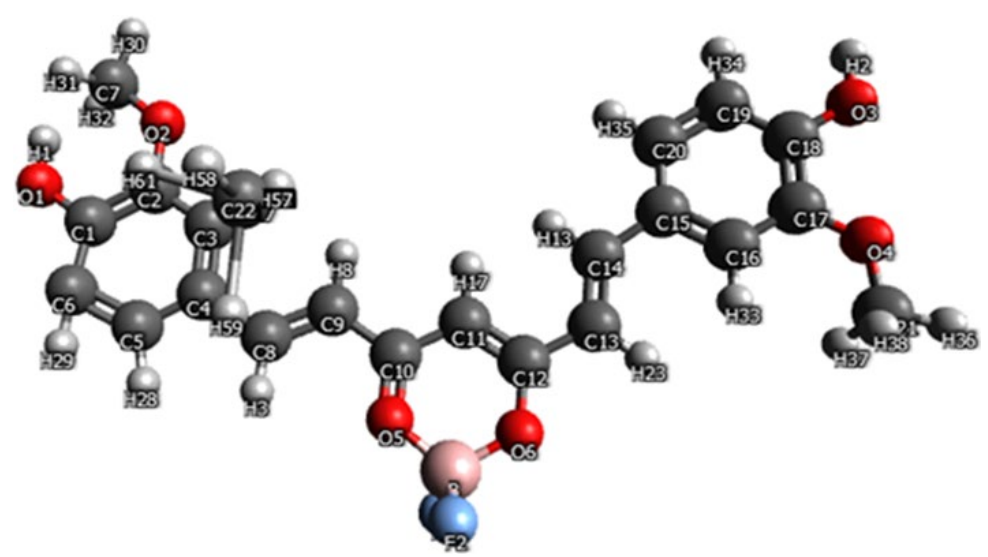

Fig 5. The configuration of Cur- $\mathrm{BF}_{2}$ showed after completing the optimal calculation based on the UFF method 
disappeared as shown in Fig. 1-2. As seen in Fig. 4, the protons of two phenolic hydroxy groups in the $\mathrm{BF}_{2}$-Cur complex were shielded by the negative charge on the boron atom, which effectively removed hydrogen atoms from those hydroxyl groups. This deprotonation caused a high charge separation between acceptor and donor units in $\mathrm{BF}_{2}$-Cur, excellent electron delocalization to $\mathrm{BF}_{2}$ unit on the structure of the complex, $\mathrm{BF}_{2}$-Cur. The excited states in the complexes were stabilized upon the binding of $\mathrm{AsO}_{3}{ }^{3-}$. The result is a bathochromic shift in the absorption band with $\mathrm{Dl}^{1 / 4} 142$ and $92.9 \mathrm{~nm}$ for $\mathrm{BF}_{2}$-Cur and curcumin, respectively. Moreover, a new emission band at $750 \mathrm{~nm}$ for $\mathrm{BF}_{2}-\mathrm{Cur}$ and $\mathrm{AsO}_{3}{ }^{3-}$ was observed. $\mathrm{A}$ schematic illustration is shown in Fig. 2.

\section{Qualitative Results of Total Arsenic}

\section{Method validation}

The standard curve equation was obtained at the best conditions such as $632 \mathrm{~nm}, \mathrm{BF}_{2}-\mathrm{Cur} 60 \%$ in ethanol, and $\mathrm{pH}=8$ for $\mathrm{As}(\mathrm{III})$ analysis. According to the absorbance at $1-25 \mu \mathrm{M}$, the equation was $\mathrm{y}=0.0027 \mathrm{x}+$ 0.0106 , with $\mathrm{R}^{2}=0.9969$.

\section{Evaluation of As(III) analytical procedure}

For As(III) analysis method applying the aboveproposed procedure, it is necessary to define the limit of detection (LoD) and limit of quantitative (LoQ) and evaluate the accuracy through the evaluation of precision and trueness of this method. The LoD of As(III) by the analytical method was determined using a linear equation to calculate the theoretical concentration of As(III). Then,

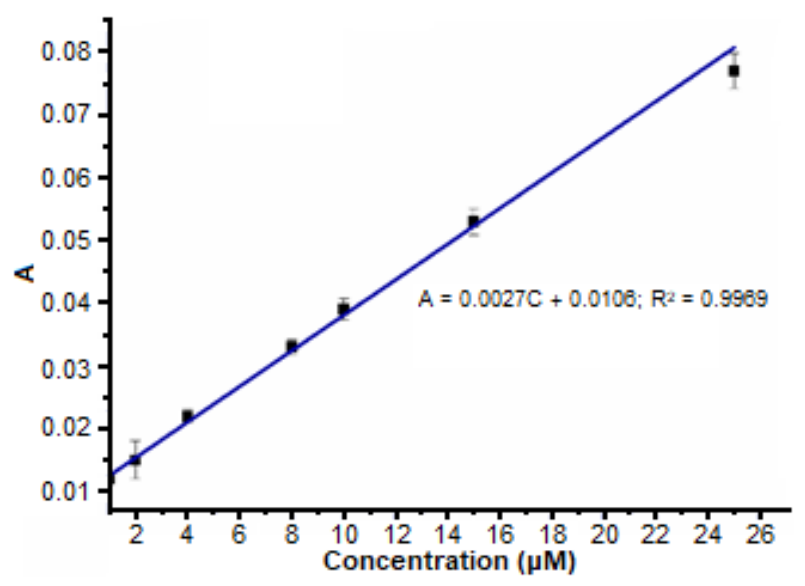

Fig 6. The linear range of As(III) the mean, $\overline{\mathrm{x}}_{0}$ and the standard deviation, $\mathrm{SD}_{0}$, were calculated in the values of $\overline{\mathrm{x}}_{0}=0.2815, \mathrm{SD}_{0}=0.1816$, respectively. The values of $\mathrm{LoD}$ and $\mathrm{LoQ}$ were calculated by the expressions of $\overline{\mathrm{x}}_{0}+3 \mathrm{SD}_{0}=0.83 \mu \mathrm{M}$ and LOQ $=\overline{\mathrm{x}}_{0}$ $+10 \mathrm{SD}_{0}=2.10 \mu \mathrm{M}$ for the blank sample, respectively.

\section{Precision}

The precision of the method was expressed quantitatively by the standard deviation. It was carried out through many analytical procedures with standard samples at the As(III) concentration of $30 \mu \mathrm{M}$, corresponding to $4.8 \mu \mathrm{M}$ after dilution. The mean concentration of As(III), $\bar{x}=29.7454$ and $\mathrm{SD}=0.2642$ were determined. The relative standard deviation, RSD $\%$, followed the expression of RSD\% $=\frac{\mathrm{SD}}{\overline{\mathrm{x}}} \times 100 \%=$ $0.89 \%$. The relative standard deviation is within the allowable range when comparing the calculated value with the maximum acceptable repeatability table at different concentrations according to AOAC (Annex $11)$, so the method precision is satisfactory.

\section{Trueness}

The $t$ standard can be used to evaluate the trueness of the method. The analytical results from 20 repeated experiments are used as the standard sample As(III) concentration of $30 \mu \mathrm{M}$ above. The mean concentration of As(III) was $\overline{\mathrm{X}}=29.7454$ and $\mathrm{SD}=0.2642$. From those results, the experimental $t$ value, $t_{t n}$ was calculated according to the expression, $\mathrm{t}_{\mathrm{tn}}=\frac{|\mu-\bar{x}|}{\mathrm{SD}}=0.967$, with $\mathrm{k}=$ $19, \alpha=0.95$ and $t_{c}=2.093$. Due to $t_{t n}<t_{c}$, there was no difference in the average value and the reference at the significant level $\alpha$, so the method was satisfactorily true. The various proportions of the conditions to analyze the total As such as $\mathrm{pH}$, equability time, the volume of $\mathrm{BF}_{2}-$ Cur solution, linear range, the limit of detection, the limit of quantification, reduced reagent, and precision (\%RSD) were tested to establish the optimal conditions as shown in Table 1.

\section{Determination the total content of arsenic in water samples}

In this work, the experiments were measured three times, calculating the $\mathrm{As}(\mathrm{III})$ concentration in the samples from the calibration curve, $y=0.0027 x+0.0106$,

\footnotetext{
Nguyen Quoc Thang et al.
} 
Table 1. The optimum conditions to analyze total As

\begin{tabular}{lll}
\hline STT & Parameters & Optimal conditions \\
\hline 1 & Absorbance wavelength & $632 \mathrm{~nm}$ \\
2 & $\mathrm{pH}$ & $7.5-8.0$ \\
3 & Solvent & Ethanol: $\mathrm{H}_{2} \mathrm{O}(60: 40, \mathrm{v} / \mathrm{v})$ \\
4 & Equabilities time & Until $70 \mathrm{~min}$ \\
5 & Volume of $\mathrm{BF}_{2}$-curcumin $(12 \mathrm{mg} / \mathrm{L})$ & $4 \mathrm{~mL}$ \\
6 & Linear range & $1-25 \mu \mathrm{mol} / \mathrm{L}$ \\
7 & Linear regression & $\mathrm{A}=0.0027 \mathrm{C}+0.0106$ \\
8 & Correlation coefficient $\left(\mathrm{r}^{2}\right)$ & 0.9969 \\
9 & Limit of detection $(\mathrm{LoD})$ & $0.83 \mu \mathrm{mol} / \mathrm{L}$ \\
10 & Limit of quantification $(\mathrm{LoQ})$ & $2.10 \mu \mathrm{mol} / \mathrm{L}$ \\
11 & Reduce reagent & $\mathrm{KI}-\mathrm{ascorbic}$ acid mixer \\
12 & Precision $(\% \mathrm{RSD})$ & $0.89 \%$ \\
\hline
\end{tabular}

Table 2. The content of As(III) and total As in water samples

\begin{tabular}{cccc}
\hline $\begin{array}{c}\text { As }(\mathrm{III}) \\
\text { (our research) }\end{array}$ & As(III) by HPLC-ICP-MS & $\begin{array}{c}\text { Total As } \\
\text { (our research) }\end{array}$ & Total As by HPLC-ICP-MS \\
\hline $37.96 \mu \mathrm{M}$ & $38.83 \mu \mathrm{M}$ & $45.06 \mu \mathrm{M}$ & $45.86 \mu \mathrm{M}$ \\
\hline
\end{tabular}

and the As(III) concentration in the original sample from the formula $\mathrm{C}_{\mathrm{As}(\text { III) original }}=6.25 \times \mathrm{C}_{\mathrm{As} \text { (III) }}$ measured. The average concentration of As(III) in the original sample was $37.96 \mu \mathrm{M}$, and the result of the HPLC-ICP-MS method for As(III) concentration was $38.93 \mu \mathrm{M}$. Total arsenic in wastewater by reducing $\mathrm{As}(\mathrm{V})$ to $\mathrm{As}(\mathrm{III})$ was $45.06 \mu \mathrm{M}$, and the result measured by the HPLC-ICP-MS method was $45.86 \mu \mathrm{M}$. These results are quite relevant and can be studied for practical applications (Table 2).

\section{- CONCLUSION}

In this study, $\mathrm{BF}_{2}$-Cur reagent was synthesized, the structure was featured, then the $\mathrm{pK}_{\mathrm{a} 1}$ and $\mathrm{pK}_{\mathrm{a} 2}$ values were determined. The results demonstrated the effectiveness of $\mathrm{BF}_{2}$-Cur reagent in analysis. In addition, $\mathrm{BF}_{2}$-Cur reagent can also be used as a specific and selective reagent to determine the concentration of As(III) and total arsenic content in a water sample by UV-Vis spectrophotometry. The $\mathrm{BF}_{2}$-Cur complex can be synthesized easily in the lab and be studied for practical applications.

\section{- REFERENCES}

[1] Saxena, G., and Bharagava, R.N., 2017, "Organic and Inorganic Pollutants in Industrial Wastes, Their Ecotoxicological Effects" in Environmental
Pollutants and Their Bioremediation Approaches, $1^{\text {st }}$ Ed., Eds. Bharagave, R.N., CRC Press, Boca Raton, Florida, US, 23-56.

[2] Li, H., Zhang, Q., Jiang, W., Collier, S., Sun, Y., and Zhang, Q., 2021, Characteristics and sources of water-soluble organic aerosol in a heavily polluted environment in Northern China, Sci. Total Environ., 758, 143970.

[3] Hanif, N.M., Adnan, S.N.N., Latif, M.T., Zakaria, Z., Abdullahand, M.P., and Othman, M.R., 2012, The composition of surfactants in river water and its influence to the amount of surfactants in drinking water, World Appl. Sci. J., 17 (8), 970-975.

[4] Lellis, B., Fávaro-Polonio, C.Z., Pamphile, J.A., and Polonio, J.C., 2019, Effects of textile dyes on health and the environment and bioremediation potential of living organisms, Biotechnol. Res. Innovation, 3 (2), 275-290.

[5] Ali, M.M., Ali, M.L., Islam, M.S., and Rahman, M.Z., 2016, Preliminary assessment of heavy metals in water and sediment of Karnaphuli River, Bangladesh, Environ. Nanotechnol. Monit. Manage., 5, 27-35.

[6] Shankar, S., Shanker, U., and Shikha, 2014, Arsenic contamination of groundwater: A review of 
sources, prevalence, health risks, and strategies for mitigation, Sci. World J., 2014, 304524.

[7] Flora, S.J.S., 2015, Handbook of Arsenic Toxicology, Academic Press, Oxford, UK.

[8] Mähler, J., Persson, I., and Herbert, R.B., 2013, Hydration of arsenic oxyacid species, Dalton Trans., 42 (5), 1364-1377.

[9] Uddin, A.H., Khalid, R.S., Khan, U.A., and Abbas, S.A., 2013, Determination of arsenic content of available traditional medicines in Malaysia using hydride generation atomic absorption spectrometry, Trop. J. Pharm. Res., 12 (6), 1053-1056.

[10] Paula, J.F.R., Froes-Silva, R.E.S., and Ciminelli, V.S.T., 2012, Arsenic determination in complex mining residues by ICP OES after ultrasonic extraction, Microchem. J., 104, 12-16.

[11] Shahlaei, M., and Pourhossein, A., 2014, Determination of arsenic in drinking water samples by electrothermal atomic absorption spectrometry after preconcentration using the biomass of Aspergillus niger loaded on activated charcoal, J. Chem., 2014, 912619.

[12] Musil, S., Matoušek, T., Currier, J.M., Stýblo, M., and Dědina, J., 2014, Speciation analysis of arsenic by selective hydride generation-cryotrapping-atomic fluorescence spectrometry with flame-in-gas-shield atomizer: Achieving extremely low detection limits with inexpensive instrumentation, Anal. Chem., 86 (20), 10422-10428.

[13] Mutic, J.J., Manojlovic, D.D., Stankovic, D., and Lolic, A.D., 2011, Development of inductively coupled plasma atomic emission spectrometry for arsenic determination in wine, Pol. J. Environ. Stud., 20 (1), 133-139.

[14] Paul, R.L., 2011, Evaluation of radiochemical neutron activation analysis methods for determination of arsenic in biological materials, Anal. Chem., 83 (1), 152-156.

[15] Babar, N.U.A., Joya, K.S., Tayyab, M.A., Ashiq, M.N., and Sohail, M., 2019, Highly sensitive and selective detection of arsenic using electrogenerated nanotextured gold assemblage, ACS Omega, 4, 13645-13657.
[16] Gamboa, J.C.M., Cornejo, L., Acarapi, J., and Squella, J.A., 2013, Determination of arsenic (III) by differential pulse polarography in the waters of Camarones area, Chile, J. Chil. Chem. Soc., 58 (4), 2031-2034.

[17] Ferrari, E., Asti, M., Benassi, R., Pignedoli, F., and Saladini, M., 2013, Metal binding ability of curcumin derivatives: a theoretical vs. experimental approach, Dalton Trans., 42 (15), 5304-5313.

[18] Jiang, T., Zhi, X.L., Zhang, Y.H., Pan, L.F., and Zhou, P., 2012, Inhibitory effect of curcumin on the $\mathrm{Al}(\mathrm{III})$-induced $\mathrm{A} \beta_{42}$ aggregation and neurotoxicity in vitro, Biochim. Biophys. Acta, Mol. Basis Dis., 1822 (8), 1207-1215.

[19] Pucci, D., Bellini, T., Crispini, A., D’Agnano, I., Liguori, P.F., Garcia-Orduña, P., Pirillo, S., Valentini, A., and Zanchetta, G., 2012, DNA binding and cytotoxicity of fluorescent curcuminbased Zn(II) complexes, Med. Chem. Commun., 3 (4), 462-468.

[20] Meza-Morales, W., Estévez-Carmona, M.M., Alvarez-Ricardo, Y., Obregón-Mendoza, M.A., Cassani, J., Ramírez-Apan, M.T., EscobedoMartínez, C., Soriano-García, M., Reynolds, W.F., and Enríquez, R.G., 2019, Full structural characterization of homoleptic complexes of diacetylcurcumin with $\mathrm{Mg}, \mathrm{Zn}, \mathrm{Cu}$, and $\mathrm{Mn}$ : Cisplatin-level cytotoxicity in vitro with minimal acute toxicity in vivo, Molecules, 24 (8), 1598.

[21] Choodum, A., Jirapattanasophon, V., Boonkanon, C., Taweekarn, T., and Wongniramalkul, W., 2020, Difluoroboron-curcumin doped starch film and digital image colorimetry for semi-quantitative analysis of arsenic, Anal. Sci., 36 (5), 577-582.

[22] Sirawatcharin, S., Saithongdee, A., Chaicham, A., Tomapatanaget, B., Imyim, A., and Praphairaksit, N., 2014, Naked-eye and colorimetric detection of arsenic(III) using difluoroboron-curcumin in aqueous and resin bead support systems, Anal. Sci., 30 (12), 1129-1134.

[23] Chaicham, A., Kulchat, S., Tumcharern, G., Tuntulani, T., and Tomapatanaget, B., 2010, Synthesis, photophysical properties, and cyanide 
detection in aqueous solution of $\mathrm{BF}_{2}$-curcumin dyes, Tetrahedron, 66 (32), 6217-6223.

[24] Zhang, Y., Tu, L., Lu, L., Li, Y., Song, L., Qi, Q., Song, H., Li, Z., and Huang, W., 2020, Screening and application of boron difluoride complexes of curcumin as colorimetric and ratiometric fluorescent probes for bisulfite, Anal. Methods, 12 (11), 1514-1521.

[25] Ran, C., Xu, X., Raymond, S.B., Ferrara, B.J., Neal, K., Bacskai, B.J., Medarova, Z., and Moore, A., 2009, Design, synthesis, and testing of difluoroboronderivatized curcumins as near-infrared probes for in vivo detection of Amyloid- $\beta$ deposits, J. Am. Chem. Soc., 131 (42), 15257-15261.

[26] Bernabé-Pineda, M., Ramírez-Silva, M.T., RomeroRomo, M., González-Vergara, E., and RojasHernández, A., 2004, Determination of acidity constants of curcumin in aqueous solution and apparent rate constant of its decomposition, Spectrochim. Acta, Part A, 60 (5), 1091-1097.

[27] Baum, L., and Ng, A., 2004, Curcumin interaction with copper and iron suggests one possible mechanism of action in Alzheimer's disease animal models, J. Alzheimer's Dis., 6 (4), 367-377.

[28] Behari, J.R., and Prakas, R., 2006, Determination of total arsenic content in water by atomic absorption spectroscopy (AAS) using vapour generation assembly (VGA), Chemosphere, 63 (1), 17-21.

[29] Klotz, E., Doyle, R., Gross, E., and Mattson, B., 2011, The equilibrium constant for bromothymol blue: A general chemistry laboratory experiment using spectroscopy, J. Chem. Educ., 88 (5), 637-639.

[30] Zabihi, F., Kiani, F., Yaghobi, M., Shahidi, S.A., and Koohyar, F., 2020, The theoretical calculations and experimental measurements of acid dissociation constant and thermodynamic properties of glycylaspartic acid in aqueous solution at different temperatures, J. Chil. Chem. Soc., 65 (2), 4759-4768.

[31] Laali, K.K., Greves, W.J., Correa-Smits, S.J., Zwarycz, A.T., Bunge, S.D., Borosky, G.L., Manna, A., Paulus, A., and Chanan-Khan, A., 2018, Novel fluorinated curcuminoids and their pyrazole and isoxazole derivatives: Synthesis, structural studies, computational/docking and in-vitro bioassay, J. Fluorine Chem., 206, 82-98.

[32] Dubbeldam, D., Vreede, J., Vlugt, T.J.H., and Calero, S., 2019, Highlights of (bio-)chemical tools and visualization software for computational science, Curr. Opin. Chem. Eng., 23, 1-13. 